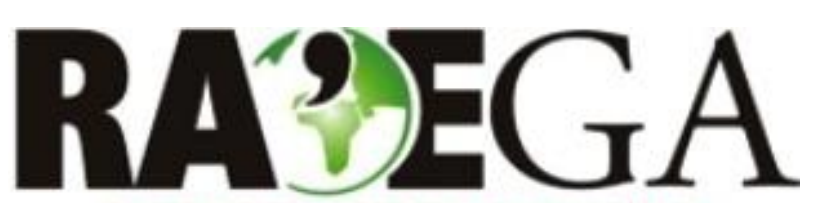

O ESPAÇO GEOGRÁFICO EM ANÁLISE

\title{
AVALIAÇÃO DA SUSTENTABILIDADE AMBIENTAL EM TRÊS PARQUES ESTADUAIS DO ESTADO DE MATO GROSSO DO SUL, NO PERÍODO ENTRE 1985 A 2014.
}

\section{ASSESSMENT OF ENVIRONMENTAL SUSTAINABILITY IN THREE STATE PARKS OF MATO GROSSO DO SUL, IN THE PERIOD 1985-2014.}

\author{
Jorge de Souza Pinto \\ Programa de Pós-Graduação em Meio Ambiente e Desenvolvimento \\ Regional na Universidade Anhanguera - UNIDERP \\ Campo Grande, MS, Brasil \\ e-mail: jorge.pinto@ufms.br
}

André Luiz Pinto Universidade Federal de Mato Grosso do Sul

Três Lagoas, MS, Brasil e-mail: andre.pinto@ufms.br

Valéria Peron de Souza Pinto

Universidade Federal de Mato Grosso do Sul

Três Lagoas, MS, Brasil e-mail:vperon@gmail.com

Ademir Kleber Morbeck de Oliveira Universidade Anhanguera - UNIDERP

Campo Grande, MS, Brasil e-mail: akmorbeckoliveira@gmail.com

Celso Correia de Souza Universidade Anhanguera - UNIDERP

Campo Grande, MS, Brasil e-mail: csouza939@gmail.com

\section{Resumo}

Três Parques Estaduais do Estado de Mato Grosso do Sul, que possuem planos de manejo em operação, foram avaliados em relação à situação de sua cobertura vegetal pelo Índice de Vegetação por Diferença Normalizada e 


\title{
AVALIAÇÃO DA SUSTENTABILIDADE AMBIENTAL EM TRÊS PARQUES ESTADUAIS DO ESTADO DE MATO GROSSO DO SUL, NO PERÍODO ENTRE 1985 A 2014.
}

relacionando os dados obtidos com sua sustentabilidade, buscando-se, apresentar a evolução do uso e ocupação da terra e do índice de vegetação, abrangendo as influências trazidas pela implantação dos parques e seus planos de manejo na preservação do ambiente e sua sustentabilidade. Foram utilizadas imagens Landsat TM 7 e Landsat LC 8 dos anos de 1985, 2000 e 2014, respectivamente, as quais foram processadas no Sistema de Informações Geográficas (SIG), por meio do uso dos softwares SIG Spring 5.2.6 e no SIG ArcGis. Os resultados obtidos mostram que os parques estaduais Nascentes do Rio Taquari, Pantanal do Rio Negro e Várzeas do Rio Ivinhema têm sofrido pressões e depleções em decorrência de usos inadequados dos recursos naturais, em suas zonas de amortecimento, que dificultam a sua conservação. Os índices NDVI, de uso e ocupação da terra obtidos mostram certa resiliência do ambiente, porém mostram, também, recuos significativos e perdas de qualidade da cobertura vegetal, prospectando-se um cenário de dificuldades em frear os impactos contra as unidades de conservação, bem como em promover a recuperação e manutenção do ambiente, diante da constatação de que ainda é incipiente a implantação efetiva dos seus planos de manejo.

Palavras-chave: cobertura vegetal; resiliência; ambiente; biodiversidade;

\begin{abstract}
Three State Parks State of Mato Grosso do Sul, which have management plans in operation, were assessed in relation to the situation of their forest cover by Normalized Difference Vegetation Index (NDVI) and relating the data obtained with its sustainability, yet seeking to present the evolution of the use and occupation of land and vegetation index, covering the influences brought about by the implementation of the parks and their management plans in preserving the environment and its sustainability. Landsat TM 7 and Landsat LC 8 images of 1985,2000 and 2014 respectively were used and were processed in GIS environment, through the use of GIS software Spring 5.2.6 and ArcGIS GIS. The results show that the state parks Headwaters of the Taquari River, Pantanal of Rio Negro and floodplains of the Ivinhema River have suffered pressures and depletions due to improper use of natural resources in their buffer zones, which hinder their conservation. The NDVI indexes and of use and occupation of land obtained by the analysis show some resilience of the environment, however, also show significant decline and loss of plant covering quality, prospecting a difficult scenario in curbing impacts over protected areas in conservation units and promoting environmental restoration and maintenance given that effective implementation of management plans is still incipient.
\end{abstract}

Key words: vegetation cover; resilience; environment; biodiversity.

\section{INTRODUÇÃO}

A conservação do ambiente no Estado de Mato Grosso do Sul celebra, a partir da implantação de Parques Estaduais, a introdução do dispositivo para 
PINTO, J. S.; PINTO, A. L.; PINTO, V. P. S.; OLIVEIRA, A. K. M.; SOUZA, C. C.

AVALIAÇÃO DA SUSTENTABILIDADE AMBIENTAL EM TRÊS PARQUES ESTADUAIS DO ESTADO DE MATO GROSSO DO SUL, NO PERÍODO ENTRE 1985 A 2014.

adotar mecanismos de manejo e preservação de unidades de conservação (UCs) e seus respectivos recursos naturais, que sintetizam importantes parcelas do bioma cerrado e pantanal no Estado. Neste intento, faz-se necessário entender e desenvolver esforços e políticas de conservação dos recursos naturais abrangidos e de suas Zonas de Amortecimento, que consideram regiões na borda das UCs que contemplam as características de cobertura vegetal e biodiversidade, contribuindo no processo de sucessão e preservação dos parques.

Os Parques Estaduais (PE) congregam Unidade de Conservação de Uso Sustentável, na qual pode coexistir o desenvolvimento de atividades de educação ambiental, pesquisas científicas e visitação, se constituindo como ambientes de potencial sustentável. Neles, o Estado tem possibilidade de desenvolver mecanismos de desenvolvimento sustentável, visando à preservação da biodiversidade do ambiente, conforme o Sistema Nacional de Unidades de Conservação da Natureza (SNUC) (BRASIL, 2000).

Sustentabilidade, de acordo com Sachs (1990, 2002), constitui-se num conceito dinâmico, com dimensões sociais, econômicas, ecológicas, culturais, ambientais, territoriais, política nacional e política internacional, no qual permitiria que ecossistemas naturais realizassem autodepuração, a destinação igualitária de investimentos públicos e a conservação da biodiversidade pelo eco-desenvolvimento, com um nível razoável de coesão social, entre outras ações.

Em Macedo et al. (2011), o conceito de sustentabilidade e seus entendimentos relativos à sustentabilidade ambiental e desenvolvimento sustentável partem das dimensões Triple Bottom Line (TBL), ou seja, os fatores econômicos, sociais e ambientais em um plano de proposições que beneficiem a manutenção dos recursos naturais, compatibilizando-os com as demandas antropogênicas e culminado em formas de garantir uma redução da depleção do ambiente.

$\mathrm{Na}$ sustentabilidade em Parques Estaduais (PE), tratada neste estudo, priorizam-se o espaço e as paisagens destas unidades, os estudos e os monitoramentos fundamentados no uso de geotecnologias, trazendo uma 
contribuição significativa para o entendimento destes e outros problemas em relação ao ambiente e as UCs, como, por exemplo, os estudos de análise multitemporal, que permitem o acompanhamento sazonal da superfície da Terra com o monitoramento da evolução dos desmatamentos, crescimento urbano e monitoramento agrícola (CAMPOS et al., 2014).

Portanto, "mudança de uso da terra" tem o significado de transformações quantitativas na paisagem, compreendido como o acréscimo ou o decréscimo de uma determinada classe de uso do solo. Assim, proporciona-se, com a análise multitemporal de cenas de imagens de satélite, de mesmos locais, em diferentes períodos, uma avaliação crítica das mudanças da paisagem apresentadas durante o tempo em estudo (BRIASSOULIS, 2000).

Com a redução das matas e florestas e os contínuos impactos e vulnerabilidades susceptíveis em UC, torna-se necessário o desenvolvimento de estratégias que possibilitem a conservação e/ou monitoramento para recuperação da vegetação remanescente.

Desta maneira, o uso de ferramentas, tais como os Sistemas de Informações Geográficas (SIG), permitem a geração de informações a pessoas incumbidas de tomar decisões, de maneira que a aquisição de informações espaciais seja eficaz ao planejamento e gestão ambiental (SIMÕES; CARDOSO, 1998).

Um dos principais elementos técnicos associado a geotecnologias, que permite o monitoramento de vegetação é o índice de vegetação por diferença normalizada (Normalized Difference Vegetation Index - NDVI), utilizado para avaliação das mudanças do vigor vegetativo das plantas, objetivando a correlação com outros parâmetros, como a biomassa ou a produtividade da vegetação.

A eficácia na utilização desta metodologia é comprovada, por exemplo, no estudo de Risso et al. (2012), no qual é avaliado o desempenho do índice de vegetação realçado (Enhanced Vegetation Index - EVI) e do índice de vegetação da diferença normalizada (NDVI), ambos do sensor "moderate resolution imaging spectroradiometer" (MODIS), para discriminar áreas de 
plantação de soja das áreas de cana-de-açúcar, pastagem, Cerrado e floresta no Estado do Mato Grosso do Sul.

Neste estudo, objetivou-se avaliar a situação em três Parques Estaduais do Estado de Mato Grosso do Sul que possuem planos de manejo, por meio da análise comparativa dos índices de vegetação por diferença normalizada, no período entre 1985 a 2014, tendo como marco divisório a elaboração dos Planos de Manejos (PM) e como parâmetros o uso e ocupação da terra nos Parques e em suas Zonas de Amortecimento (ZA).

\section{MATERIAL E MÉTODOS}

\section{1 Áreas de estudo}

O presente estudo foi realizado em três Parques Estaduais de Mato Grosso do Sul, o Parque Estadual do Pantanal do Rio Negro (PEPRN), coordenadas $53^{\circ} 30^{\prime} 0 "$ a $53^{\circ} 07^{\prime} 0 " \mathrm{O}$ e $18^{\circ} 13^{\prime} 20^{\prime \prime}$ a $18^{\circ} 00^{\prime} 0 " \mathrm{~S}$, o Parque Estadual das Nascentes do rio Taquari (PENRT), coordenadas $17^{\circ} 59^{\prime}$ a $18^{\circ}$

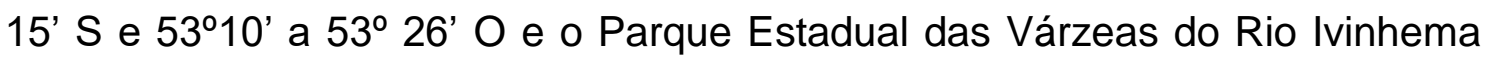

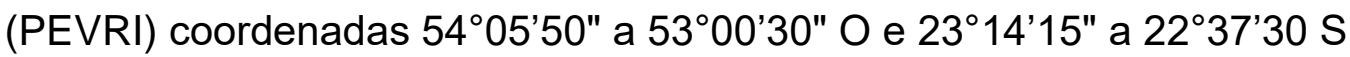

A localização das áreas dos parques PEPRN, PENRT e PEVRI, individualmente, bem como a localização da BH-RPY e BH-RPR, estão compreendidas e identificadas por delimitação vetorial cartográfica, disposta nas bases de referência do Sistema Interativo de Suporte ao Licenciamento Ambiental - SISLA/IMASUL, na área situada entre as coordenadas $59^{\circ} 62^{\prime} 4654229^{\prime \prime}$ a $49^{\circ} 69^{\prime} 06238069 "$ o e $25^{\circ} 04^{\prime} 97906622^{\prime \prime}$ a $16^{\circ} 58^{\prime} 67008864 "$ S, circunscrição do Estado de Mato Grosso do Sul (Figura 1). 


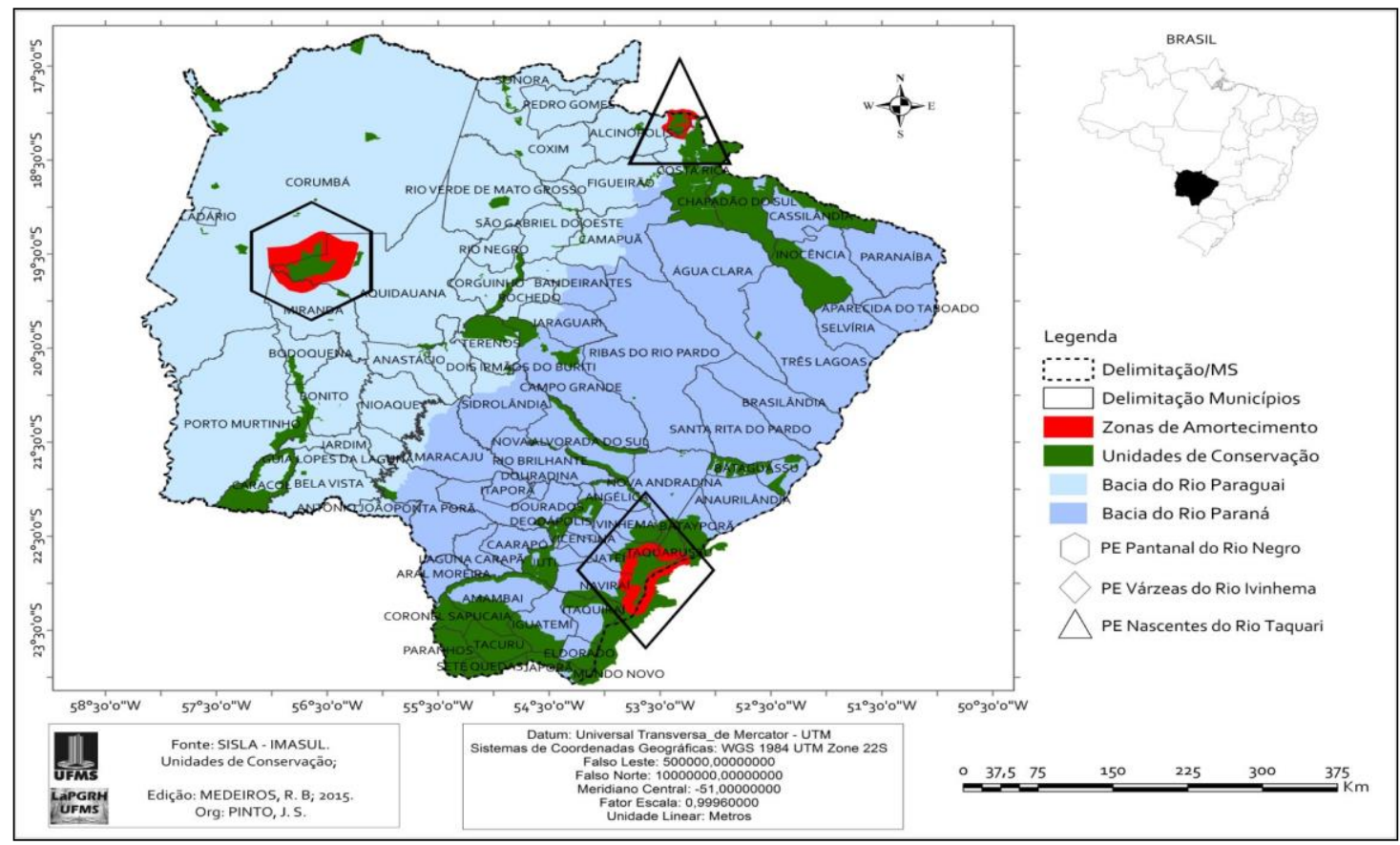

Figura 1. Localização dos Parques Estaduais Várzeas do Rio Ivinhema, Nascentes do Rio Taquari e Pantanal do Rio Negro, Estado de Mato Grosso do Sul, Brasil, em 2014. Fonte: Sistema Interativo de Suporte ao Licenciamento Ambiental - SISLA/IMASUL (2014).

O Parque Estadual do Pantanal do Rio Negro (PEPRN), criado em 2000, está localizado na Bacia Hidrográfica do Rio Paraguai (BH-RPY), nos municípios de Aquidauana e Corumbá, com uma área de 78.302,9 hectares.

Essa área engloba grande parte de um extenso sistema de irrigação, como o brejão do Rio Negro, formado por lagoas permanentes, regionalmente conhecidas como baías e canais de drenagem (corixos e vazantes). Também são encontrados os chamados campos limpos, cobertos por gramíneas nativas e nas áreas mais altas, chamadas de cordilheiras e capões, ocorrendo a presença de espécies arbóreas típicas, tais como a piúva (Handroanthus impetiginosus (Mart. ex DC.) Mattos.) e o manduvi (Sterculia apetala (Jacq.) Karst.). O Parque Estadual do Pantanal do Rio Negro está inserida exclusivamente no bioma Pantanal, o qual compreende uma área de 152.389 $\mathrm{km}^{2}$, abrangendo a Bolívia, o Paraguai e o Brasil, país em que está situada a maior parte deste bioma (PARANHOS FILHO et al., 2014).

O Parque Estadual das Nascentes do rio Taquari (PENRT), criado em 1999, com uma área de 30.618,9 hectares, está localizado a nordeste do 
Estado, abrangendo os municípios de Costa-Rica e Alcinópolis, possuindo em sua área as três nascentes do Rio Taquari (Bacia do Paraguai).

Essa área é predominantemente coberta pelo bioma Cerrado, com a presença das fitofisionomias de cerradão, cerrado sensu stricto, campos sujos, campos rupestres, veredas, além de áreas de floresta estacional semidecidual. Como espécies vegetais encontradas, pode-se citar, entre outras, Handroanthus aureus Mattos, Jacaranda decurrens Cham., Aspidosperma macrocarpon Mart., Copaifera langsdorffii Desf., Enterolobium contortisiliquum (Vell.) Morong, Annona coriacea Mart., Aspidosperma tomentosum Mart., Kielmeyera coriacea Mart. \& Zucc, conforme dados constantes de seu PM.

As características fisiográficas das áreas da região de borda, que influenciam o PENRT, são de superfície aplanada, onde ocorriam originalmente áreas de acumulação inundáveis, com amplos vales de fundo plano e raso, conhecidas como veredas e era ocupada originalmente por campo sujo, sendo que atualmente essa área está quase totalmente coberta por extensas lavouras de soja, milho e algodão.

Já o Parque Estadual das Várzeas do Rio Ivinhema (PEVRI), criado em 1998, possui área de 73.315,1 hectares, localizados nos municípios de Jateí, Naviraí e Taquarussu. areão Parque apresenta áreas de Floresta Estacional Semidecidual, zonas de transição Cerrado/Floresta Estacional Semidecidual e locais de vegetação pioneira de influência lacustre/fluvial, localmente/popularmente denominada varjão. Apresenta a espécies como Eichhornia crassipes (Mart.) Solms, E. azurea (Sw.) Kunth., Echinodorus longipetalus Mich. e Aeschynomene sensitiva Sw, além de espécies arbóreas em áreas secas, tais como Chamaecrista eitenorum (H.S. Irwin \& Barneby) H.S. Irwin \& Barneby., C. desvauxii (Colladon) Killip, Hymenaea courbaril L., C. langsdorffii, Peltophorum dubium (Spreng.) Taub. e Pterogyne nitens.

\section{METODOLOGIA}

Para a delimitação das áreas destinadas aos três PE estudados, utilizouse de arquivos shape de zoneamento de unidades de conservação disponibilizados por meio do Sistema de Licenciamento Ambiental - 
PINTO, J. S.; PINTO, A. L.; PINTO, V. P. S.; OLIVEIRA, A. K. M.; SOUZA, C. C.

AVALIAÇÃO DA SUSTENTABILIDADE AMBIENTAL EM TRÊS PARQUES ESTADUAIS DO ESTADO DE MATO GROSSO DO SUL, NO PERÍODO ENTRE 1985 A 2014.

SISLA/IMASUL, para a confecção das cartas de cobertura vegetal e uso e ocupação da terra dos PE, com o desenvolvimento do NDVI.

$\mathrm{Na}$ elaboração das cartas de cobertura vegetal e uso da terra foram feitas interpretações de imagens de satélite Landsat 5/TM, bandas 3, 4 e 5 dos anos de 1985 e 2000, adquiridas gratuitamente no site do INPE (Instituto Nacional de Pesquisas Espaciais). Com relação à imagem de 2014, esta foi obtida a partir da interpretação de imagens Landsat 8/OLI, bandas 4, 5 e 6, disponibilizadas por meio do site da USGS (United States Geological Survey). Para todos os parques foram utilizadas as mesmas bandas citadas.

Com relação ao PE das Várzeas do Rio Ivinhema, foram realizadas a interpretação das imagens de satélite dos dias 10/01/1985, 25/04/2000 e 10/01/2014, órbita 224 e ponto 76. E para o PE das Nascentes do Rio Taquari, foram utilizadas imagens dos dias 10/01/1985, 11/05/2000 e 02/04/2014, órbita 224 e ponto 73, para a confecção das cartas de cobertura vegetal e de uso e ocupação da terra do PE, como também para desenvolvimento do NDVI.

$\mathrm{Na}$ interpretação da cobertura vegetal e uso da terra no PE do Pantanal do Rio Negro foram utilizadas duas imagens da órbita 226, pontos 73 e 74, dos dias 08/11/1985, 28/07/2000 e 26/04/2014, pois o Parque ficou localizado na junção das duas imagens, tanto para a confecção das cartas de cobertura vegetal e de uso e ocupação da terra, como também para desenvolvimento do NDVI.

Todas essas imagens foram importadas e georreferenciadas por meio de pontos de controle passíveis de identificação na imagem, sendo utilizada uma imagem ortorretificada pancromática da área como base, para registrar as novas imagens de satélite, trabalhados no SIG Spring 5.2.6 e no SIG ArcGis 10.

Após o georreferenciamento, o contraste foi executado no SIG Spring ${ }^{\circledR}$ 5.2.6 a fim de melhorar a qualidade da imagem, utilizando a opção equalizar histograma. A partir deste contraste, foi realizada a interpretação da cobertura vegetal e uso da terra por meio de classificação não supervisionada por regiões, onde foi utilizado o classificador Histograma, cuja liminar de aceitação 
foi de $95 \%$. Na classificação, foram definidas classes temáticas da cobertura vegetal e uso da terra:

$\checkmark$ Vegetação Antrópica de Pastagens, com área de plantio predominante de braquária (Brachiaria spp.);

$\checkmark$ Vegetação Natural Campestre, gramíneas e ervas nativas da região, tais como: rabo-de-burro (Andropogon bicornis L.) e Aristida longifolia Trin;

$\checkmark$.Vegetação Natural Campestre Úmido, com vegetação rasteira de áreas úmidas ou alagadas, tais como Andropogon hypogynus Hack. e Paspalum virgatum L.;

$\checkmark$ Áreas Antrópicas Urbanizadas, sendo: construções de casas, pavimentação de ruas, calçamentos e terrenos sem cobertura vegetal com fins urbanos;

$\checkmark$ Áreas Antrópicas Agrícolas de Lavouras Temporárias, com plantio de grãos, tais como: soja (Glycine max L.) e milho (Zea mays L.), verduras e hortaliças, que fazem parte do cinturão verde de Campo Grande;

$\checkmark$ Corpos d'água, com presença de rios e córregos;

$\checkmark$ Vegetação Natural Florestal, cobertas por vegetação de porte arbóreo do bioma Cerrado, como cerradões, cerrado e matas estacionais.

Finalmente, a imagem classificada foi importada no ArcGis 10, para corrigir os erros que o Spring acarreta na classificação, analisando cada região e alterando aquelas que apresentavam incongruências, alterando seu atributo de acordo com a realidade mostrada na imagem de satélite.

A elaboração de Índices de NDVI (Normalized Difference Vegetation Index) buscou qualificar as áreas de acordo com a quantidade de vegetação existente nos locais pesquisados.

$\mathrm{Na}$ elaboração das cartas de NDVI, foram feitas interpretações de imagens de satélite Landsat 5/TM, bandas 3 e 4 dos anos de 1985 e 2000, adquiridas gratuitamente no site do INPE - Instituto Nacional de Pesquisas Espaciais. Com relação à imagem de 2014 foi realizada a interpretação de imagens Landsat 8/OLI, bandas 4 e 5, disponibilizadas no site da USGS. Para todos os parques foram utilizadas as mesmas bandas citadas.

Utilizou-se o ArcGis 10, da ferramenta Spatial Analyst Tools > Map Algebra> Raster Calculator, sendo utilizado o cálculo do NDVI seguindo a 
equação: $N D V I=I V P-V / I V P+V$, onde IVP é o valor da reflectância da banda no Infravermelho próximo e $\mathrm{V}$ é o valor de reflectância da banda no vermelho.

Para a interpretação das imagens geradas dos PE, com a classificação NDVI, os intervalos utilizados para as classes foram divididos em dez classes, com os índices variando de -1 à +1 . Portanto, os que apresentam classes maiores são referentes à vegetação arbórea densa ou vegetação arbórea em crescimento e os de classes menores são os solos expostos ou corpos hídricos.

\section{RESULTADOS E DISCUSSÃO}

Os resultados da avaliação da evolução da cobertura vegetal e uso e ocupação da terra no PENRT e PEPRN (Figuras 2 e 3) indicam avanços significativos das atividades antrópicas de agropecuária, que tem carreado pressões e depleções relevantes às unidades de conservação e seu entorno.

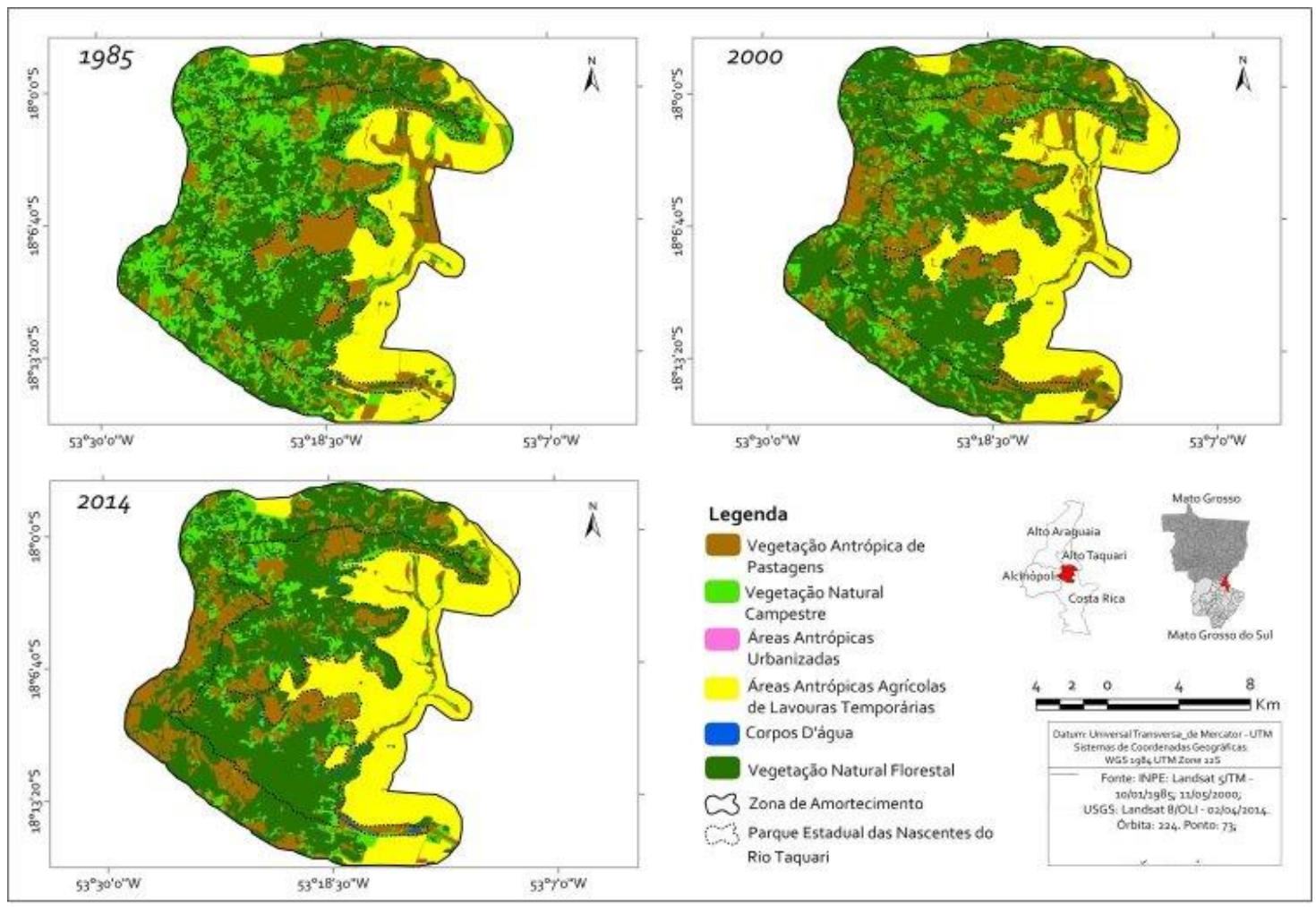

Figura 2. Cobertura vegetal e uso da terra no Parque Estadual Nascentes do Rio Taquari, Estado de Mato Grosso do Sul, entre 1985, 2000 e 2014. 
No PENRT (Figura 2) toda sua borda é ocupada com atividade pecuária e agricultura, com plantio de soja e algodão; dentro da área do Parque também existem áreas agrícolas e de pastagens, que entre outras consequências, contribuem para a fragmentação de habitat e depleção da biodiversidade.

A cobertura vegetal e o uso da terra no PEPRN (Figura 3) apresentam características distintas de outros Parques, pois sua conformidade e localização são influenciadas pelo ciclo das águas do Pantanal sul-matogrossense. E, portanto, possui uma proteção natural em relação às atividades antrópicas de maiores impactos ao ambiente.

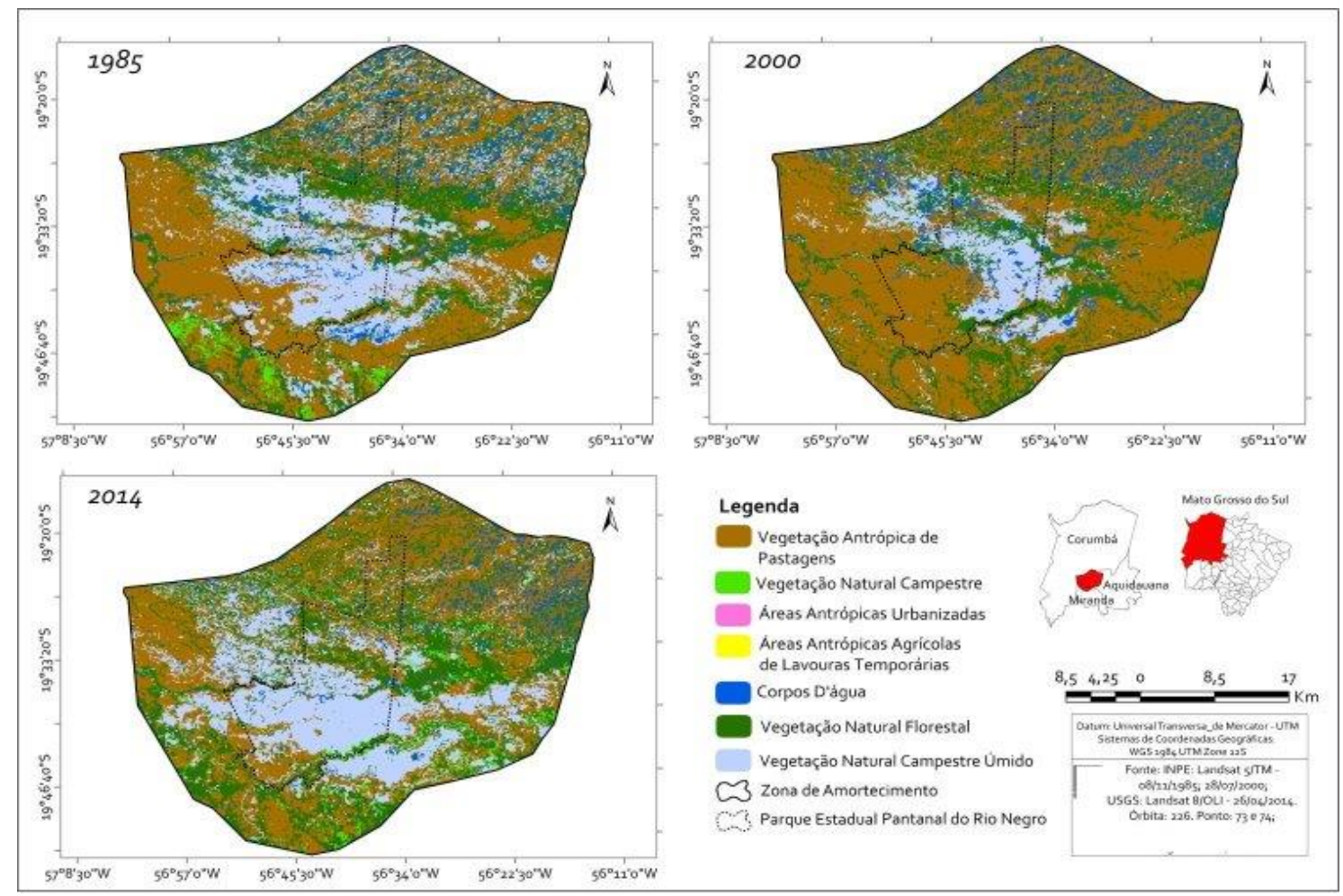

Figura 3. Cobertura vegetal e uso da terra no Parque Estadual Pantanal do Rio Negro, Estado de Mato Grosso do Sul, entre 1985, 2000 e 2014.

Existem no PEPRN, como mostra a Figura 3, certa resiliência ambiental no período de 1985, 2000 e 2014, mesmo estando com pressão da fronteira pecuária bovina e dos constantes incêndios, comuns na região, que ocorrem no outono e inverno, sendo alguns de origem antrópica, que visam renovar as pastagens, e que muitas vezes saem de controle, invadindo a área do Parque.

Embora as áreas em geral do PEPRN sofram as consequências das ações humanas e, também, da não efetivação de seu plano de manejo, a 
PINTO, J. S.; PINTO, A. L.; PINTO, V. P. S.; OLIVEIRA, A. K. M.; SOUZA, C. C.

AVALIAÇÃO DA SUSTENTABILIDADE AMBIENTAL EM TRÊS PARQUES ESTADUAIS DO ESTADO DE MATO GROSSO DO SUL, NO PERÍODO ENTRE 1985 A 2014.

unidade representa um estuário de biodiversidade do Pantanal com toda sua riqueza de fauna e flora, que deve ser preservada.

Na evolução das atividades antrópicas no PENRT e PEPRN (Tabela 1), são mostrados os problemas decorrentes das atividades antrópicas, principalmente a agropecuária, os incêndios, e a não regularização fundiária de áreas dos Parques. Além disso, há áreas, ainda, que precisam ser regularizadas, pois continuam sofrendo as ações de depleção em seus ambientes.

Com as análises da cobertura vegetal e uso da terra (Tabela 1) pode-se confirmar a baixa eficiência no manejo e conservação do PENRT, pois no período de 1985 a 2014 ocorreu uma evolução da ocupação de áreas de forma nociva à preservação do ambiente, com o avanço da pressão das atividades antrópicas agrícolas de cultivo da soja, do milho e de algodão, aumentando em $56,5 \%$ na área ZA e 47,9 \% na área do PE, além de pastagens com crescimento de $16,5 \%$ na área (ZA) e 23,8 \% na área do $P E$.

Esses aumentos de áreas relacionadas às atividades antrópicas, dentro do parque, significam que o plano de manejo não está sendo colocado em prática, ameaçando a conservação do parque. No mesmo período, verificou-se também um declínio de áreas preservadas e um aumento da fragmentação dos recursos naturais, com recuo de 42,4\% na área de vegetação natural campestre dentro do parque e 55,94\% na zona de amortecimento (Tabela 1), agora ocupadas por pastagens ou áreas agrícolas na ZA.

A urbanização na Zona de Amortecimento (ZA) também apresentou um aumento de $15,8 \%$, indicando que está ocorrendo um aumento de população no entorno do parque, indicando possíveis pressões futuras.

A vegetação florestal aumentou $8,8 \%$ no parque e diminuiu $20,3 \%$ no entorno do mesmo, resultado similar ao dos recursos hídricos, que aumentaram 51,3\% dentro do parque e diminuíram na zona de amortecimento em $67,5 \%$ (Tabela 1 ). 
PINTO, J. S.; PINTO, A. L.; PINTO, V. P. S.; OLIVEIRA, A. K. M.; SOUZA, C. C.

AVALIAÇÃO DA SUSTENTABILIDADE AMBIENTAL EM TRÊS PARQUES ESTADUAIS DO ESTADO DE MATO GROSSO DO SUL, NO PERÍODO ENTRE 1985 A 2014.

Tabela 1. Evolução do uso e ocupação da terra no Parque Estadual Nascentes do Rio Taquari e Parque Estadual Pantanal do Rio Negro (PQ) e nas zonas de amortecimento (ZA), na Bacia Hidrográfica do Rio Paraguai, Mato Grosso do Sul.

\begin{tabular}{|c|c|c|c|c|c|c|c|c|c|c|c|c|c|c|c|c|c|c|c|c|c|c|c|c|}
\hline \multirow{3}{*}{$\begin{array}{l}\text { Classes da cobertura } \\
\text { vegetal e uso da terra }\end{array}$} & \multicolumn{12}{|c|}{ Áreas do PENRT em (mil. ha.) e em \% } & \multicolumn{12}{|c|}{ Áreas do PEPRN em (mil. ha.) e em \% } \\
\hline & \multicolumn{4}{|c|}{1985} & \multicolumn{4}{|c|}{2000} & \multicolumn{4}{|c|}{2014} & \multicolumn{4}{|c|}{1985} & \multicolumn{4}{|c|}{\begin{tabular}{|c|}
2000 \\
\end{tabular}} & \multicolumn{4}{|c|}{2014} \\
\hline & $P Q /$ ha. & $P Q / \%$ & ZA/ha. & $Z A / \%$ & $P Q /$ ha. & $\mathrm{PQ} / \%$ & ZA/ha. & ZA/\% & $P Q /$ ha. & $\mathrm{PQ} / \%$ & ZA/ha. & $\mathrm{ZA} / \%$ & $P Q /$ ha. & $\mathrm{PQ} / \%$ & ZA/ha. & $\mathrm{ZA} / \%$ & $P Q /$ ha. & $\mathrm{PQ} / \%$ & ZA/ha. & ZA $\%$ & $P Q /$ ha. & $\mathrm{PQ} / \%$ & ZA/ha. & $\mathrm{ZA} / \%$ \\
\hline Veget. Antrópica Pastagens & 5,7 & $7 \%$ & 8,3 & $10 \%$ & 7,9 & $9 \%$ & 9,5 & $11 \%$ & 6,7 & $8 \%$ & 10,3 & $12 \%$ & 23,8 & $6 \%$ & 160,1 & $39 \%$ & 35,4 & $9 \%$ & 182,6 & $44 \%$ & 20,9 & $5 \%$ & 181,8 & $44 \%$ \\
\hline Veget. Natural Campestre & 6,6 & $8 \%$ & 8,8 & $11 \%$ & 4,3 & $5 \%$ & 3,7 & $4 \%$ & 3,8 & $5 \%$ & 3,9 & $5 \%$ & 0,1 & $0 \%$ & 7,5 & $2 \%$ & - & $0 \%$ & 0,3 & $0 \%$ & 0,6 & $0 \%$ & 8,7 & $2 \%$ \\
\hline $\begin{array}{l}\text { Veget. Natural Campestre } \\
\text { Úmido }\end{array}$ & - & $0 \%$ & - & $0 \%$ & - & $0 \%$ & - & $0 \%$ & - & $0 \%$ & - & $0 \%$ & 38,0 & $9 \%$ & 61,0 & $15 \%$ & 22,2 & $5 \%$ & 45,7 & $11 \%$ & 41,2 & $10 \%$ & 54,0 & $13 \%$ \\
\hline Áreas Antrópicas Urbanizadas & - & $0 \%$ & 0,0 & $0 \%$ & - & $0 \%$ & 0,0 & $0 \%$ & - & $0 \%$ & 0,0 & $0 \%$ & - & $0 \%$ & - & $0 \%$ & - & $0 \%$ & - & $0 \%$ & - & $0 \%$ & - & $0 \%$ \\
\hline $\begin{array}{l}\text { Áreas Agric. Lavoura } \\
\text { Temporária }\end{array}$ & 0,2 & $0 \%$ & 15,1 & $18 \%$ & 0,2 & $0 \%$ & 19,8 & $24 \%$ & 0,3 & $0 \%$ & 22,3 & $27 \%$ & - & $0 \%$ & - & $0 \%$ & - & $0 \%$ & - & $0 \%$ & - & $0 \%$ & - & $0 \%$ \\
\hline $\begin{array}{l}\text { Corpos D'água - Rios e } \\
\text { Córregos }\end{array}$ & 0,2 & $0 \%$ & 0,3 & $0 \%$ & 0,2 & $0 \%$ & 0,2 & $0 \%$ & 0,3 & $0 \%$ & 0,1 & $0 \%$ & 4,5 & $1 \%$ & 26,9 & $6 \%$ & 5,6 & $1 \%$ & 31,7 & $8 \%$ & 1,6 & $0 \%$ & 16,8 & $4 \%$ \\
\hline Veget. Natural Florestal & 18,5 & $22 \%$ & 19,8 & $24 \%$ & 18,5 & $22 \%$ & 19,1 & $23 \%$ & 20,1 & $24 \%$ & 15,8 & $19 \%$ & 12,2 & $3 \%$ & 81,9 & $20 \%$ & 15,4 & $4 \%$ & 77,0 & $19 \%$ & 14,3 & $3 \%$ & 76,1 & $18 \%$ \\
\hline Área total em hectares & \multicolumn{4}{|c|}{83,5} & \multicolumn{4}{|c|}{83,5} & \multicolumn{4}{|c|}{83,5} & \multicolumn{4}{|c|}{415,9} & \multicolumn{4}{|c|}{415,9} & \multicolumn{4}{|c|}{415,9} \\
\hline
\end{tabular}


PINTO, J. S.; PINTO, A. L.; PINTO, V. P. S.; OLIVEIRA, A. K. M.; SOUZA, C. C.

AVALIAÇÃO DA SUSTENTABILIDADE AMBIENTAL EM TRÊS PARQUES ESTADUAIS DO ESTADO DE MATO GROSSO DO SUL, NO PERÍODO ENTRE 1985 A 2014.

No caso da vegetação, o aumento dessas áreas dentro do parque está relacionado a processos de sucessão, em que a vegetação de porte arbóreo começa a substituir antigas áreas de vegetação campestre no processo de sucessão.

Por outro lado, a redução dos recursos hídricos na ZA é causada pela retirada de vegetação florestal, levando a perda por assoreamento de parte de córregos e lagoas. Dentro do parque, o aumento na área está provavelmente relacionado à recuperação de cobertura vegetal que permitiu que nascentes que estavam inertes voltassem a alimentar os córregos e lagoas, portanto, aumentando o volume de corpos hídricos no parque.

O Parque Estadual do Pantanal do Rio Negro também apresenta alterações em suas fisionomias e, por estar em área de inundação sazonal, não possui áreas de agricultura ou urbanizadas.

As áreas de pastagens implantadas, vegetação campestre e vegetação campestre úmida, além dos corpos hídricos, costumam apresentar grandes alterações em seus valores dentro do parque, pois estão relacionadas ao período de inundação, que é sazonal e cobre diferentes extensões de terra na dependência do ano e intensidade da inundação.

Desta maneira, os valores apresentados na Tabela 1 são variáveis. Porém, pode-se perceber que dentro do parque continuam existindo áreas com a presença de gramíneas exóticas, tais como Brachiaria spp. e que a área no entorno do parque, em sua maior parte, é cercada pelo mesmo gênero de gramínea.

A vegetação florestal é mais constante e, dentro do parque, aumentou $17,5 \%$, resultado da sucessão vegetal em antigas áreas de pastagens abandonadas. Já na zona de amortecimento diminui 7,04\%.

Tais resultados indicam para o desmatamento para formação de novas áreas de gramíneas exóticas, demonstrando que, mesmo em parques mais isolados, a ameaça da alteração das zonas de amortecimento é sempre um fator de risco, pois os protocolos a serem seguidos em ZA normalmente não são cumpridos.

Dentre as unidades de conservação do Estado, os PENRT e PEPRN são um patrimônio estratégico da biodiversidade do Estado, por servirem o 
manancial hídrico da planície pantaneira e abrigarem uma importante reserva de fauna e flora do bioma úmido de cerrado, sendo necessária ênfase em políticas públicas que possibilitem sua adequada conservação e, consequentemente, a preservação da bacia hidrográfica do Rio Paraguai.

Na região da bacia hidrográfica do Rio Paraná, o PEVRI é um importante ecótono da região Sul do Estado, principal responsável por abrigar a reprodução da ictiofauna existente entre as usinas hidrelétricas de Jupiá, em Três Lagoas e Sérgio Motta, em Porto Primavera, sendo resultante da compensação ambiental por estes impactos ambientais.

O local originou-se da aquisição de uma fazenda e, assim, a cobertura vegetal e uso da terra ainda sofrem os resquícios de sua atividade anterior (Figura 4), com muitas áreas de pastagens plantadas, drenagens inadequadas e o próprio desmatamento, que é o carro chefe da depleção da unidade, que ocasiona erosão, avulsões, solapamentos e outras mudanças na paisagem.

Por ser uma região de expansão das atividades agrícolas de produção de grãos, bem como de produção de cana-de-açúcar e pastagens, são representativas as pressões que essas atividades exercem na zona de amortecimento do parque.

Outros dois fatores que apresentam forte influência negativa são os constantes incêndios e o extrativismo clandestino de recursos naturais, principalmente, do ginseng (Pfaffia glomerata (Sprengel) Pedersen), que se dão em decorrência da não efetivação adequada do plano de manejo. A extração do ginseng é um problema grave, pois os coletores, para facilitar sua retirada, costumam atear fogo na vegetação.

Ainda, em relação à cobertura vegetal e uso da terra e as pressões nas áreas de amortecimento do PEVRI, as consequências resultantes obtiveram um aumento de $209 \%$ na área de pastagens dentro do parque e $31,2 \%$ na ZA. Estes aumentos estão relacionados à redução da área florestal, com diminuição de $63,2 \%$ no parque e $45,4 \%$, na ZA (Figura 4). 


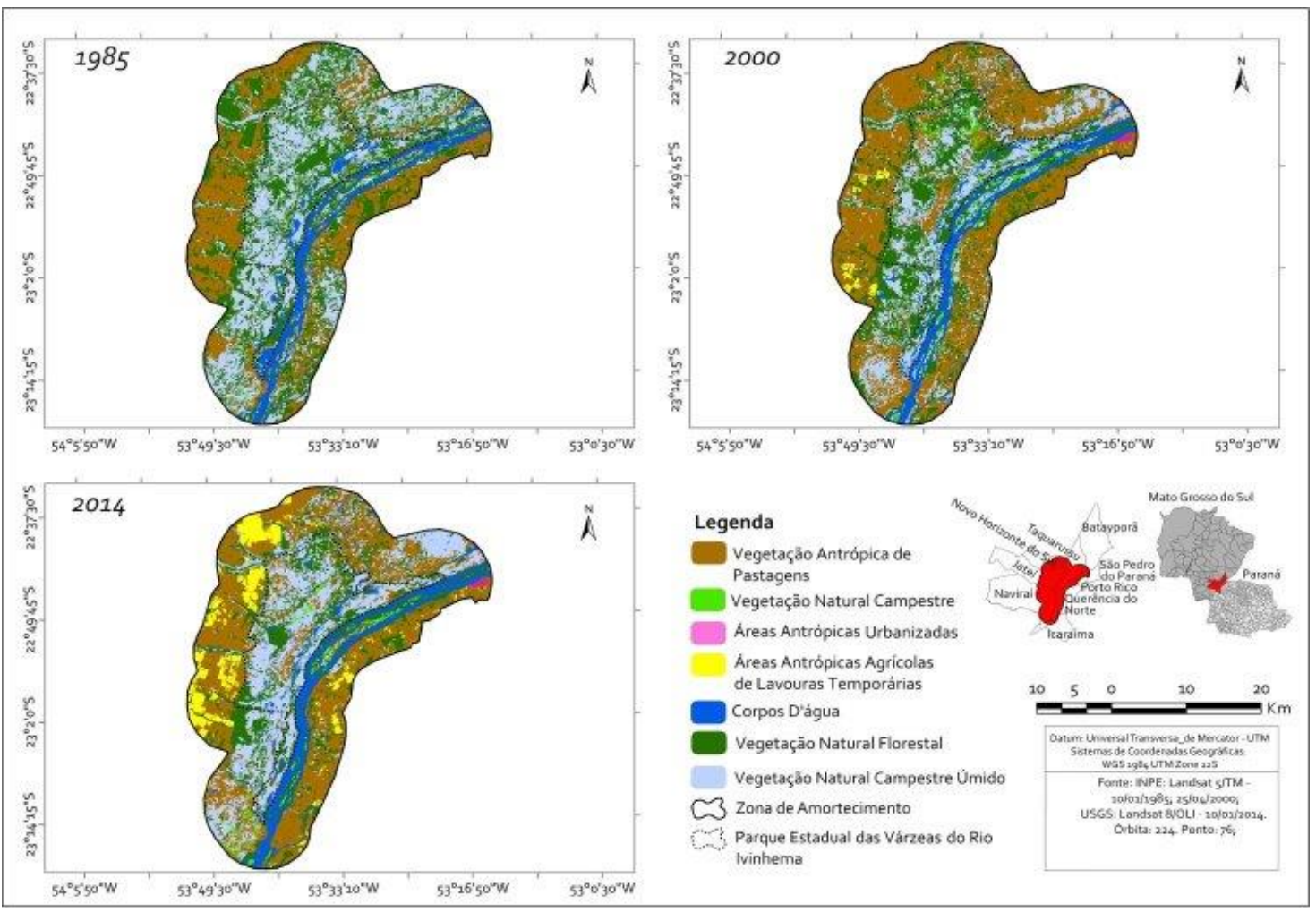

Figura 4. Cobertura vegetal e uso da terra no Parque Estadual Várzeas do Rio Ivinhema, Mato Grosso do Sul, entre 1985, 2000 e 2014.

Outro problema observado é o expressivo aumento nas áreas urbanas no entorno do parque, mais de $1.218,5 \%$ e também das áreas agrícolas, mais $19.600 \%$, indicando que o entorno da área do parque começa a ser mais densamente ocupado e utilizado por atividades anteriormente de pouca expressão (Tabela 2).

Ainda na Tabela 2, em relação às áreas campestres, é mostrado um aumento no parque de $61,5 \%$ e na ZA, aumento de $273,9 \%$, áreas campestres úmidas, aumento de $23,4 \%$ no parque e na $Z A$, redução de $29,19 \%$ e nos corpos d'água uma redução de $27 \%$ no parque e aumento de $7,6 \%$ na ZA. Os valores, de maneira similar ao Parque Estadual do Pantanal do Rio Negro, são influenciados pela dinâmica de inundação do rio Ivinhema, que na dependência do ano, pode ocupar diferentes extensões de terra. 
Tabela 2. Evolução do uso e ocupação da terra no Parque Estadual Várzeas do Rio Ivinhema (PEVRI) e nas zonas de amortecimento (ZA), na Bacia Hidrográfica do Rio Paraná, Mato Grosso do Sul

\begin{tabular}{|c|c|c|c|c|c|c|c|c|c|c|c|c|}
\hline \multirow{3}{*}{$\begin{array}{l}\text { Classes da cobertura } \\
\text { vegetal e uso da terra }\end{array}$} & \multicolumn{12}{|c|}{ Áreas do PEVRI em (mil. ha.) e em \% } \\
\hline & \multicolumn{4}{|c|}{1985} & \multicolumn{4}{|c|}{2000} & \multicolumn{4}{|c|}{2014} \\
\hline & PQ/ha. & $P Q / \%$ & ZA/ha. & $\mathrm{ZA} \%$ & PQ/ha. & $P Q / \%$ & ZA/ha. & ZA $\%$ & $P Q / h a$. & $P Q / \%$ & ZA/ha. & $\mathrm{ZA} / \%$ \\
\hline Veget. Antrópica Pastagens & 2,5 & $1 \%$ & 74,5 & $25 \%$ & 8,6 & $3 \%$ & 105,7 & $36 \%$ & 7,8 & $3 \%$ & 97,8 & $33 \%$ \\
\hline Veget. Natural Campestre & 0,4 & $0 \%$ & 0,8 & $0 \%$ & 1,9 & $1 \%$ & 2,6 & $1 \%$ & 0,6 & $0 \%$ & 2,8 & $1 \%$ \\
\hline $\begin{array}{l}\text { Veget. Natural Campestre } \\
\text { Úmido }\end{array}$ & 33,0 & $11 \%$ & 55,3 & $19 \%$ & 27,7 & $9 \%$ & 38,1 & $13 \%$ & 40,7 & $14 \%$ & 39,3 & $13 \%$ \\
\hline Áreas Antrópicas Urbanizadas & 0,0 & $0 \%$ & 0,0 & $0 \%$ & 0,0 & $0 \%$ & 0,0 & $0 \%$ & 0,0 & $0 \%$ & 0,4 & $0 \%$ \\
\hline $\begin{array}{l}\text { Áreas Agric. Lavoura } \\
\text { Temporária }\end{array}$ & 0,0 & $0 \%$ & 0,0 & $0 \%$ & 0,0 & $0 \%$ & 3,0 & $1 \%$ & 0,0 & $0 \%$ & 19,6 & $7 \%$ \\
\hline $\begin{array}{l}\text { Corpos D'água - Rios e } \\
\text { Córregos }\end{array}$ & 6,0 & $2 \%$ & 24,2 & $8 \%$ & 4,0 & $1 \%$ & 27,0 & $9 \%$ & 4,4 & $1 \%$ & 26,1 & $9 \%$ \\
\hline Veget. Natural Florestal & 31,6 & $11 \%$ & 68,3 & $23 \%$ & 31,3 & $11 \%$ & 46,8 & $16 \%$ & 20,0 & $7 \%$ & 37,3 & $13 \%$ \\
\hline Área total em hectares & \multicolumn{4}{|c|}{296,7} & \multicolumn{4}{|c|}{296,7} & \multicolumn{4}{|c|}{296,7} \\
\hline
\end{tabular}

A partir da Tabela 2, o que se depreende da situação mostrada no parque e entorno é a acelerada redução da cobertura florestal, relacionada a queimadas e extração ilegal de madeira dentro do parque e ocupação por atividades antrópicas em seu entorno.

Esses fatores ameaçam a manutenção da biodiversidade do parque e seu funcionamento. Embora em MS o PEVRI seja a UC que mais acrescenta recursos do ICMS Ecológico às prefeituras dos municípios de Bataguassu, Naviraí e Jatei.

A reciprocidade desses municípios em relação ao parque é muito baixa, dada a importância do mesmo, o que tem reflexos cruciais na estruturação de ações de recuperação e conservação do parque e efetivação do plano de manejo.

A evolução do NDVI no Parque Estadual Nascentes do Taquari, Figura 5 e Tabela 3, indica comportamento decrescente da cobertura vegetal, no qual, em 1985, a faixa de concentração dos índices era de 0,4 a 0,8. Já em 2014, estão na faixa entre 0,2 a 0,6, apontando um recuo importante na cobertura vegetal e problemas na conservação dos recursos naturais existentes no local. 


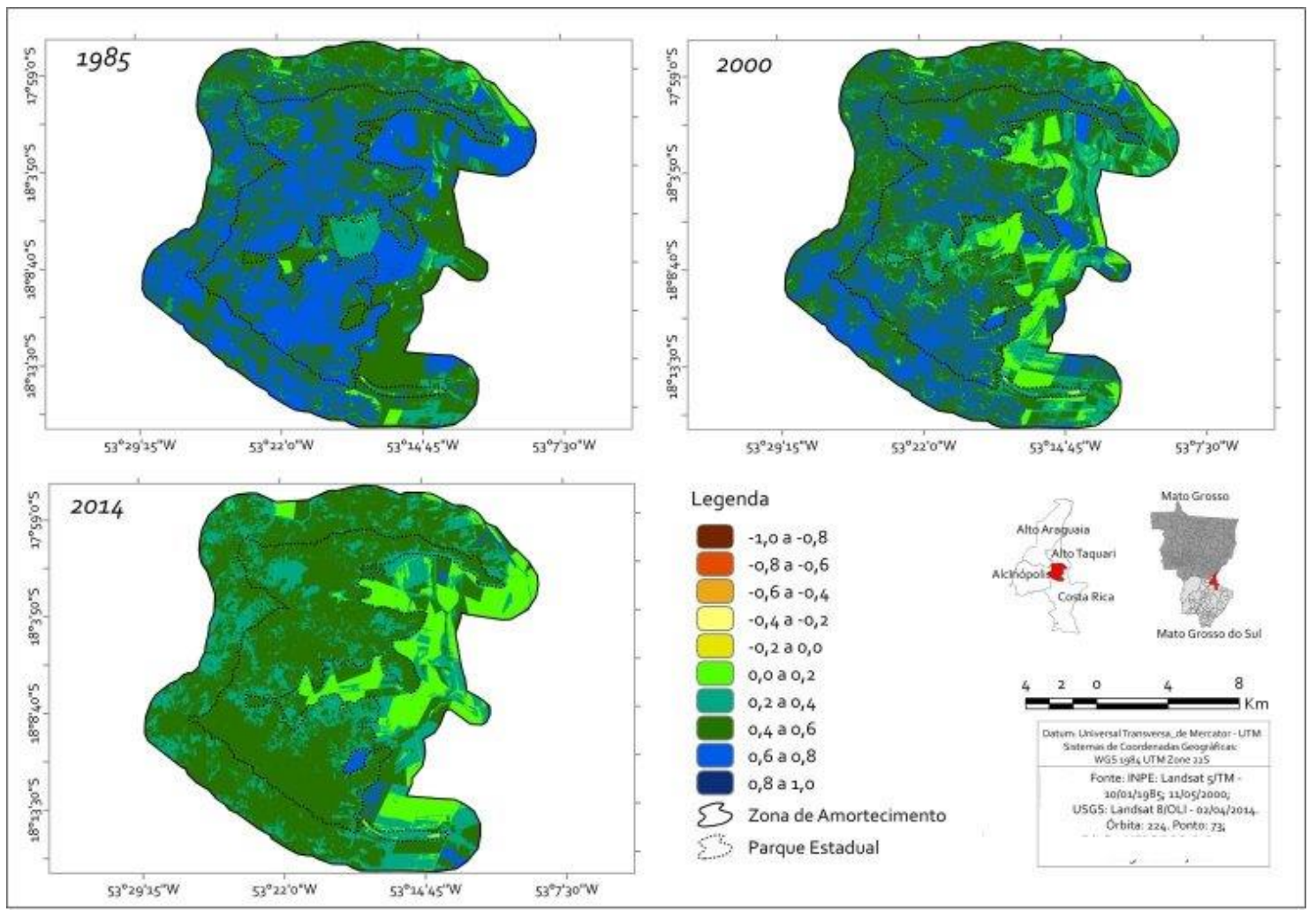

Figura 5. Carta de NDVI (Normalized Difference Vegetation Index) do Parque Estadual Nascentes do Rio Taquari, Mato Grosso do Sul, entre 1985 e 2014.

O PENRT apresenta uma situação de vegetação mediana (Tabela 3), pois em 1985 tinha 45\% de sua área com NDVI entre 0,2 a 0,4 e $36 \%$ de sua área com NDVI entre 0,4 a 0,6, tendo ainda $11 \%$ da área com NDVI entre 0,6 a 0,8 , que representavam um resultado expressivo em termos de conservação.

Em 2014, nota-se o recuo dos níveis de conservação da vegetação, com $66 \%$ de sua área (273.402,58 ha.) com NDVI entre 0,2 a 0,4 e $25 \%$ de área (103.732,32 ha.) com NDVI entre 0,4 a 0,6, não apresentando mais nenhuma área com NDVI entre 0,6 a 0,8, o que representa um aumento nas áreas com problemas de conservação. (Tabela 3 )

No PEPRN, a situação da cobertura vegetal (Tabela 3) apresentava em 1985 o valor de $47 \%$ de sua área com NDVI entre 0,4 a 0,6 e 42\% com NDVI entre 0,6 a 0,8. A situação em termos de cobertura da vegetação em 2014 apresenta recuo dos níveis de conservação no PENRT, com $58 \%$ de sua área com índice entre 0,4 a 0,6 e 40\% de área com NDVI entre 0,0 a 0,4.

Tal condição analisada revela as dificuldades que tem enfrentado a UC para manter sua biodiversidade vegetal e, consequentemente, sua importância 
como área de preservação. A situação da cobertura vegetal observada no PEVRI (Tabela 3) representava em 1985 o valor de $56 \%$ de sua área com NDVI entre 0,4 a 0,6 e 30\% de sua área com NDVI entre 0,6 a 0,8 em termos de cobertura da vegetação.

Em 2014, o PEVRI apresenta recuo na conservação, com $43 \%$ de sua área com NDVI entre 0,4 a 0,6 e 48\% com NDVI entre 0,0 a 0,4. Tais dados podem revelar que embora o parque apresente certa resiliência de sua vegetação, é importante que seja efetivado melhor seu plano de manejo, pois o ambiente já começa a indicar que os problemas ambientais citados estão alterando a qualidade do hábitat.

Para o NDVI no mesmo período do Parque Estadual do Pantanal do Rio Negro, verifica-se que em 1985 predominavam índices de 0,2 a 0,8 de cobertura vegetal e em 2014 situou-se entre 0,0 a 0,6. Esses dados também apontam uma redução da cobertura de maneira mais intensa e uma ameaça à manutenção do local em suas características naturais, o que pode ser observado na Figura 6 e Tabela 3.

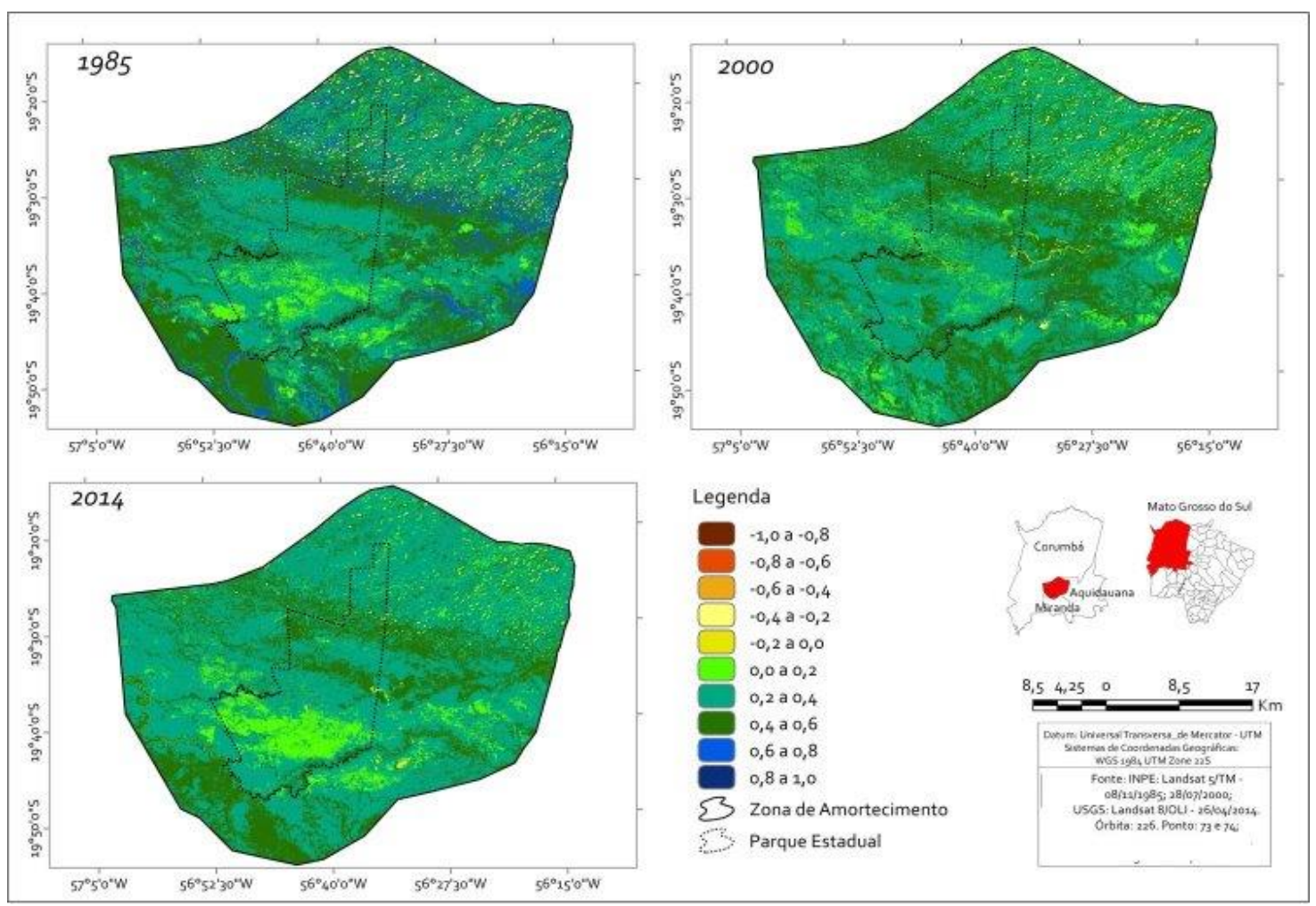

Figura 6. Carta de NDVI (Normalized Difference Vegetation Index) do Parque Estadual Pantanal do Rio Negro, Mato Grosso do Sul, entre 1985 e 2014. 
PINTO, J. S.; PINTO, A. L.; PINTO, V. P. S.; OLIVEIRA, A. K. M.; SOUZA, C. C.

AVALIAÇÃO DA SUSTENTABILIDADE AMBIENTAL EM TRÊS PARQUES ESTADUAIS DO ESTADO DE MATO GROSSO DO SUL, NO PERÍODO ENTRE 1985 A 2014. 
PINTO, J. S.; PINTO, A. L.; PINTO, V. P. S.; OLIVEIRA, A. K. M.; SOUZA, C. C.

AVALIAÇÃO DA SUSTENTABILIDADE AMBIENTAL EM TRÊS PARQUES ESTADUAIS DO ESTADO DE MATO GROSSO DO SUL, NO PERÍODO ENTRE 1985 A 2014.

Tabela 3. Evolução da área em hectares e em percentual do índice NDVI (Normalized Difference Vegetation Index) dos Parques Estaduais do Estado do Mato Grosso do Sul, entre 1985 e 2014

\begin{tabular}{|c|c|c|c|c|c|c|c|c|c|c|c|}
\hline \multirow{2}{*}{ Parques } & \multirow{2}{*}{ Periodo } & \multicolumn{10}{|c|}{ CLASSES DOS INDICES NDVI } \\
\hline & & $-1,0$ a $-0,8$ & $-0,8$ a $-0,6$ & $-0,6$ a $-0,4$ & $-0,4$ a $-0,2$ & $-0,2$ a 0,0 & 0,0 a 0,2 & 0,2 a 0,4 & 0,4 a 0,6 & 0,6 a 0,8 & 0,8 a 1,0 \\
\hline \multirow{6}{*}{$\underset{\mathbf{r}}{\mathfrak{\underline { \mathbf { x } }}}$} & 1985 & 3,87 & 6,40 & 119,25 & $2.121,48$ & $6.429,34$ & $23.130,36$ & $187.209,19$ & $150.918,01$ & $45.923,01$ & 0,09 \\
\hline & $1985 / \%$ & $0,0009 \%$ & $0,0015 \%$ & $0,03 \%$ & $0,51 \%$ & $1,55 \%$ & $5,56 \%$ & $45,02 \%$ & $36,29 \%$ & $11,04 \%$ & $0,00 \%$ \\
\hline & 2000 & 2,70 & 32,38 & 271,25 & $3.097,12$ & $3.954,91$ & $34.334,19$ & $226.439,54$ & $143.048,99$ & $4.679,56$ & 0,36 \\
\hline & $2000 / \%$ & $0,0006 \%$ & $0,0078 \%$ & $0,07 \%$ & $0,74 \%$ & $0,95 \%$ & $8,26 \%$ & $54,45 \%$ & $34,40 \%$ & $1,13 \%$ & $0,0001 \%$ \\
\hline & 2014 & 0,00 & 0,00 & 0,00 & 4,86 & $2.835,01$ & $35.885,87$ & $273.402,58$ & $103.732,32$ & 0,36 & 0,00 \\
\hline & $2014 / \%$ & $0,00 \%$ & $0,00 \%$ & $0,00 \%$ & $0,0012 \%$ & $0,68 \%$ & $8,63 \%$ & $65,74 \%$ & $24,94 \%$ & $0,0001 \%$ & $0,00 \%$ \\
\hline \multirow{6}{*}{$\begin{array}{l}z \\
\underline{\alpha} \\
\underline{\alpha} \\
\underline{a}\end{array}$} & 1985 & 0,00 & 0,17 & 0,62 & 4,31 & 60,14 & 696,85 & $7.992,30$ & $39.383,26$ & $35.360,66$ & 44,09 \\
\hline & $1985 / \%$ & $0,00 \%$ & $0,0002 \%$ & $0,0007 \%$ & $0,0052 \%$ & $0,07 \%$ & $0,83 \%$ & $9,57 \%$ & $47,14 \%$ & $42,33 \%$ & $0,05 \%$ \\
\hline & 2000 & 0,27 & 0,99 & 2,34 & 28,09 & 75,55 & $8.585,74$ & $14.568,10$ & $38.933,76$ & $21.344,77$ & 2,79 \\
\hline & $2000 / \%$ & $0,0003 \%$ & $0,0012 \%$ & $0,0028 \%$ & $0,03 \%$ & $0,09 \%$ & $10,28 \%$ & $17,44 \%$ & $46,60 \%$ & $25,55 \%$ & $0,003 \%$ \\
\hline & 2014 & 0,00 & 0,00 & 0,00 & 0,00 & 41,94 & $10.697,85$ & $23.111,82$ & $48.735,64$ & 955,15 & 0,00 \\
\hline & $2014 / \%$ & $0,00 \%$ & $0,00 \%$ & $0,00 \%$ & $0,00 \%$ & $0,05 \%$ & $12,81 \%$ & $27,66 \%$ & $58,34 \%$ & $1,14 \%$ & $0,00 \%$ \\
\hline \multirow{6}{*}{$\begin{array}{l}\overline{\tilde{q}} \\
\text { 㟧 }\end{array}$} & 1985 & 1,70 & 74,48 & $10.464,41$ & $11.391,14$ & $2.279,29$ & $3.143,58$ & $13.983,46$ & $167.034,16$ & $88.297,05$ & 16,73 \\
\hline & $1985 / \%$ & $0,0006 \%$ & $0,018 \%$ & $2,52 \%$ & $2,74 \%$ & $0,55 \%$ & $0,76 \%$ & $3,36 \%$ & $40,18 \%$ & $21,24 \%$ & $0,0040 \%$ \\
\hline & 2000 & 25,62 & 505,38 & $17.963,21$ & $2.371,37$ & $1.148,01$ & $6.681,97$ & $31.394,76$ & $182.922,60$ & $53.670,89$ & 2,16 \\
\hline & $2000 / \%$ & $0,0086 \%$ & $0,12 \%$ & $4,32 \%$ & $0,57 \%$ & $0,28 \%$ & $1,61 \%$ & $7,55 \%$ & $44,00 \%$ & $12,91 \%$ & $0,0005 \%$ \\
\hline & 2014 & 0,00 & 0,00 & 0,00 & 224,95 & $22.587,12$ & $4.757,13$ & $136.578,11$ & $127.968,76$ & $4.569,93$ & 0,00 \\
\hline & $2014 / \%$ & $0,00 \%$ & $0,00 \%$ & $0,00 \%$ & $0,05 \%$ & $5,43 \%$ & $1,14 \%$ & $32,85 \%$ & $30,78 \%$ & $1,10 \%$ & $0,00 \%$ \\
\hline
\end{tabular}


Em relação ao Parque Estadual Várzeas do Rio Ivinhema (Figura 7 e Tabela 3), a concentração dos índices obtidos indicam que em 1985 concentrava os índices NDVI na faixa de 0,4 a 0,8 e, em 2014, na faixa de 0,2 a 0,6, de maneira similar ao encontrado para o PENRT.

Embora revele declínio no índice NDVI da cobertura vegetal, os dados mostram que pode ter havido influências positivas na vegetação com a criação do parque, por retardar um declínio maior em função do uso anterior pela exploração agropecuária (Figura 7).

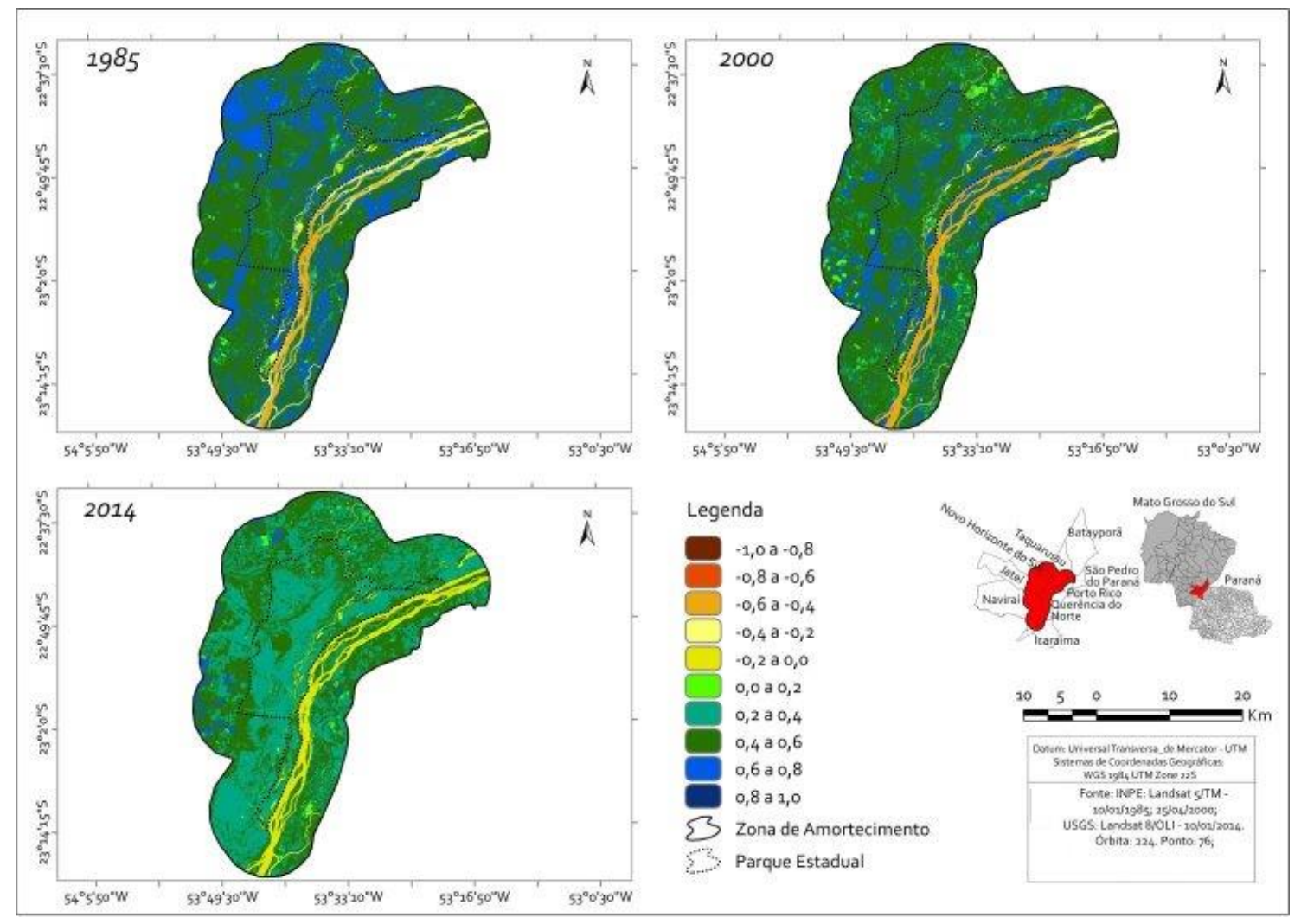

Figura 7. Carta de NDVI (Normalized Difference Vegetation Index) do Parque Estadual Várzeas do Rio Ivinhema, Mato Grosso do Sul, entre 1985 e 2014.

Esta redução, no caso do PEVRI, está principalmente relacionada à diminuição da cobertura vegetal observada dentro e fora do parque. LIMA et al. (2013) discutem e relacionam a capacidade do NDVI em posicionar o tipo de ocupação do solo e a cobertura vegetal, associando-os a corpos d'água e matas, como maneira de identificar os riscos de danos irrecuperáveis, o que talvez esteja acontecendo no PREVI (Figura 7). 
Kumar et al (2014) também indicaram que a qualificação do uso da terra e da cobertura vegetal é outro fator que possibilita a avaliação da sustentabilidade de conservação de parques, pois o uso do NDVI possibilita avaliar os níveis vegetais em áreas de várzeas que, em acompanhamentos no tempo e espaço, podem indicar os níveis de degradação e comprometimento do ambiente e sua biodiversidade.

Os resultados deste tipo de análise permitem abordagens dinâmicas do uso do NDVI, como no estudo de Galvanin et al. (2014), trabalhando com o NDVI comparativamente na discriminação das fitofisionomias de três ambientes do Pantanal de Cáceres-MT e Andrade et al. (2012), avaliando parâmetros biofísicos de superfície do Bioma Pantanal com a aplicação de geotecnologias.

No estudo de Sallo et al. (2014), utilizou-se o NDVI para estimar alguns componentes do balanço de radiação em áreas distintas (floresta secundária, reflorestamento com eucaliptos e cultivos agrícolas) no município de Lucas do Rio Verde/MT, o que possibilitou para todos esses trabalhos uma avaliação correta da situação ambiental em questão.

A vulnerabilidade do ambiente, diante das inúmeras pressões das atividades antropogênicas, exige a constante avaliação das condições de depleção. Assim, possibilitam a viabilização de ações mitigadoras, pois a capacidade de resiliência do ambiente em unidade de conservação somente é possível com avaliações que considerem os aspectos socioeconômicos circunvizinhos de cada unidade. E, ainda, a qualificação de sua cobertura vegetal, como forma de mensurar a evolução da preservação e as razões da depleção do ambiente como discutido em Briassoulis et al. (2000), Rocha et al. (2012), Campos et al. (2014) e Rubira e Souza (2015).

Não apenas as áreas dos parques, mas também as áreas que deveriam amortizar ou mitigar as pressões sobre o ambiente das UCs têm sofrido pressões, comprometendo sua qualidade de cobertura vegetal, principalmente arbórea, com perda considerável, o que corrobora para os resultados de conservação obtidos no estudo e alerta para a necessidade de busca de soluções para que os planos de manejo sejam efetivados, aumentando a 
perspectiva de continuidade de preservação, considerada uma parcela importante de biodiversidade e recursos naturais.

Pode-se observar que existe um déficit significativo em relação às zonas de amortecimento, que deveriam oferecer proteção a biodiversidade dos parques. Porém, em muitas situações verifica-se seu uso inadequado, o que promove mais rapidamente a desestabilização das áreas dos parques.

Neste estudo, foram verificadas as principais dificuldades em relação à conservação dos parques estaduais. Contudo, tem-se a perspectiva de que o cenário pode ser modificado a partir de políticas públicas de fomento ao pagamento por serviços ambientais, como o caso do ICMS Ecológico, aumento da fiscalização e responsabilização dos infratores a partir de compensações ambientais, bem como de uma adequação de dotações orçamentárias que garantam recursos aos órgãos públicos estaduais e municipais para investir em conservação e preservação do ambiente.

\section{CONCLUSÕES}

Embora os planos de manejo apresentem-se relativamente em consonância com as normas do IBAMA (Instituto Brasileiro do Meio Ambiente e dos Recursos Naturais Renováveis) e, ainda, apresentem incipiente efetivação de suas prerrogativas em relação à ocupação e conservação da cobertura de vegetação das UCs estudadas, verificou-se um declínio na cobertura vegetal dos PEPRN, PENRT e PEVRI, conduzido principalmente pelo avanço da exploração agropecuária.

Os índices NDVI de 1985 a 2014 evoluíram negativamente, situando-se entre 0,0 a 0,4. Estes dados demonstram recuos que aproximam a qualificação da cobertura vegetal de área de risco em todos os aspectos importantes de conservação e sustentabilidade dos parques, que seriam uso e ocupação adequada da terra e, também, preservação e recuperação da cobertura de vegetação, conclusões confirmadas pelas quedas de valores de NDVI em todas as áreas. 


\section{AGRADECIMENTOS}

Ao IMASUL - Instituto de Meio Ambiente de Mato Grosso do Sul, gerencia de Unidades de Conservação, pelas informações e apoio para a realização do estudo. A CAPES (Coordenação de Aperfeiçoamento de Pessoal de Nível Superior) pela bolsa de estudos concedida.

\section{REFERÊNCIAS BIBLIOGRÁFICAS}

ANDRADE, R. G.; SediYAMA, G. C.; PAZ, A. D.; LIMA, E. D. P.; FACCO, A. G. Geotecnologias aplicadas à avaliação de parâmetros biofísicos do Pantanal. Pesquisa Agropecuária Brasileira, Brasília, v. 47, n. 9, p. 1227-1234, 2012.

BRASIL. Lei no 9.985 de 18 de julho de 2000. Regulamenta o art. 225, § 10, incisos I, II, III e VII da Constituição Federal, institui o Sistema Nacional de Unidades de Conservação da Natureza (SNUC) e dá outras providências. Diário Oficial (da) República Federativa do Brasil, Brasília, seção 1, pt. 1, 19 jul. 2000.

BRIASSOULIS, H. Analysis of land use change: theoretical and modeling approaches. 1ed. Virginia: Regional Research Institute, West Virginia University, 2000.

CAMPOS, S.; GOBBI, T. T.; RECHE, A. M. Imagens digitais aplicadas no estudo da análise multitemporal da cobertura vegetal e uso da terra numa micro bacia. Periódico Eletrônico Fórum Ambiental da Alta Paulista, São Paulo, v. 10, n. 2, p. 1-8, 2014.

GALVANIN, E. A. S.; NEVES, S. M. A. S.; CRUZ, C. B. M.; NEVES, R. J.; JESUS, P. H. H.; KREITLOW, J. P. Avaliação dos índices de vegetação NDVI, SR e TVI na discriminação de fitofisionomias dos ambientes do Pantanal de Cáceres/MT. Ciência Florestal, Santa Maria, v. 24, n. 3, p. 707-715, 2014. 
KUMAR, L.; SINHA, P.; TAYLOR, S. Improving image classification in a complex wetland ecosystem through image fusion techniques. Journal of Applied Remote Sensing, Orlando, v. 8, n. 1, p. 083616-083616, 2014.

LIMA, G. C.; SILVA, M. L. N.; CURI, N.; SILVA, M. A.; OLIVEIRA, A. H.; AVANZI, J. C.; UMMUS, M. E. Avaliação da cobertura vegetal pelo índice de vegetação por diferença normalizada (IVDN). Revista Ambiente \& Água - An Interdisciplinary Journal of Applied Science, Taubaté, v. 8, n. 2, p. 52-64, 2013.

MACEDO, M. A. S.; FERREIRA, A. F. R.; CíPOLA, F. C. Análise do nível de sustentabilidade das unidades federativas do Brasil e das Capitais: um estudo sob as perspectivas econômica, social e ambiental. Revista de Gestão Social e Ambiental - RGSA, São Paulo, v. 5, n. 3, p. 73-89, 2011.

PARANHOS FILHO, A. C.; MOREIRA, E. S.; OLIVEIRA, A. K. M.; PAGOTTO, T. C. S.; MIOTO, C. L. Análise da variação da cobertura do solo no Pantanal de 2003 a 2010 através de sensoriamento remoto. Revista de Engenharia Sanitária e Ambiental, Rio de Janeiro, v. 19, n. especial, p. 69-76, 2014.

RISSO, J.; RIZZI, R.; RUDORFF, B. F. T.; ADAMI, M.; SHIMABUKURO, Y. E.; FORMAGGIO, A. R.; EPIPHANIO, R. D. V. Índices de vegetação Modis aplicados na discriminação de áreas de soja. Pesquisa Agropecuária Brasileira, Brasília, v. 47, n. 9, p. 1317-1326, 2012.

ROCHA, G. F.; FERREIRA, L. G.; FERREIRA, N. C.; FERREIRA, M. E. Detecção de desmatamentos no bioma Cerrado entre 2002 e 2009: padrões, tendências e impactos. Revista Brasileira de Cartografia, Rio de Janeiro, n. 63/03, p. 341-349, 2012. 
RUBIRA, F. G.; SOUZA, M. L. Análise multitemporal da degradação ambiental no parque municipal do cinquentenário, Maringá-PR. Revista Geografar, Curitiba, v. 9, n. 2, p. 30-61, 2015.

SACHS, I. Desarrollo sustentable, bio-industrialización descentralizada y nuevas configuraciones rural urbanas. Los casos de India y Brasil. Pensamiento Iberoamericano, Madrid, v. 46, p. 235-256, 1990.

SACHS, I. Caminhos para o desenvolvimento sustentável. 2ed. Rio de Janeiro: Garamond, 2002. 96p.

SALLO, F. S.; FRANÇA, M. S.; MORAIS, D. M.; RODRIGUES, R.; BIUDES, M. S. Estimativa de componentes do balanço de radiação em diferentes tipos de uso e cobertura do solo. Ambiente \& Água: An Interdisciplinary Journal of Applied Science, Taubaté, v. 9, n. 2, p. 347-358, 2014.

SIMÕES, L. B.; CARDOSO, L. G. Análise da distribuição da vegetação nativa na Bacia do Ribeirão Lavapés, Botucatu/SP, através de Sistema de Informações Geográficas. Energia na Agricultura, Botucatu, v. 13, n. 3, p. 1-9, 1998. 